nature of the work done. A useful index is felt to be the degree of complexity of special respiratory support and other therapy required by the patients. In this series active measures to secure and maintain a patent airway were required in over $40 \%$ of patients, while mechanical support to ventilation itself was needed in $25 \%$. The need for the presence of fully trained anaesthetists in this situation is self-evident.

As acute reversible intrinsic renal failure (acute tubular necrosis) is a not uncommon complication in these patients the amount of special therapy required in this respect also gives some indication of the nature of the work done. Over $15 \%$ of the patients required one or other of the recognized forms of special renal therapy. While the number of patients undergoing haemodialysis is never great they tend to be long-term patients, and thus the risk of serum hepatitis is always present in a respiratory intensive care unit. This risk is aggravated by the high incidence of arterial and venous blood sampling required for proper patient management. Additional hazards are presented by the frequency of multiple blood transfusions and the occasional unsuspected carrier. This situation emphasizes the need for more stringent precautions to protect staff and for such units to be designated high-risk areas when considering the problem of possible compensation for medical and nursing staff.4

A major hazard remains that of cross-infection, since these gravely ill patients are especially vulnerable to this complication. The problem is made more difficult when it is seen that some $10 \%$ of admitted patients already have a significant respiratory infection as judged clinically and bacteriologically. Most infected patients are admitted from other areas of the hospital, especially the postoperative cases and those with medical conditions. Every available measure must be rigorously applied to limit this risk, including adequate ventilation of the ward, scrupulous sterilization of apparatus, employment of "one-use" equipment, and constant bacteriological surveillance of all patients. This unit employs positive-pressure ventilation and two isolation cubicles in addition to wide spacing of beds, and all known methods of control are constantly in operation and under critical review. Prophylactic antibiotic therapy with its wellknown risk is avoided. ${ }^{5}$ Despite all precautions $10 \%$ of patients acquire a respiratory infection of minor or major significance after admission, particularly the long-stay patients with a prolonged exposure time. Eternal vigilance is obviously the price of safety in this respect.

Finally, it would be naive and misleading to regard every living patient transferred from the intensive care unit as having fully recovered. Only adequate follow-up will show the quality of recovery and whether a happy and useful person has been returned to the community. As an indication, however, of the value and efficacy of the intensive approach to treatment of these critically ill patients it may suffice to observe that during the 10-year period under review the mortality rate in severe chest injuries alone fell from $52 \%$ to $25 \cdot 8 \%$.

We wish to express our deep appreciation of the continued support in the management of these patients afforded by the nursing and ancillary staff of the intensive care unit. We are also grateful for the unfailing co-operation of our medical, laboratory, and technical colleagues. Finally, our thanks are due to Mrs. Helen Maxwell, secretary to the intensive care unit, and Miss Ann Taggart, of the department of medical records of the Royal Infirmary.

\section{References}

1 Working Party of British Medical Association's Planning Unit, Intensive Care (Report No. 1). London, British Medical Association, 1967.

2 Campbell, D., Reid, J. M., Telfer, A. B. M., and Fitch, W., British Medical fournal, 1967, 4, 255.

Department of Health and Social Security, Hepatitis and the Treatment of Chronic Renal Failure. London, H.M.S.O., 1972.
enartiont

5 Price, D. J. E., and Sleigh, J. D., Lancet, 1970, 2, 1213.

- Sullam, I. A., Mackey, W. A., and Bain, W. H., British fournal of Surgery, $1970,57,722$.

\title{
Subungual Malignant Melanoma: Difficulty in Diagnosis
}

\author{
BARBARA LEPPARD, ,K. V. SANDERSON， F. BEHAN
}

British Medical fournal, 1974, 1, 310-312

\section{Summary}

Subungual malignant melanoma developed on both great toes of a 61-year-old woman. The lesions had been diagnosed elsewhere as ingrowing toenails and had been treated as such for two years. The difficulty in clinical diagnosis is illustrated by the description of three other patients with subungual malignant melanoma. The tumour should be considered as a possible cause of any persistent abnormality of the nail bed or the nail itself, especially if it is pigmented.

\footnotetext{
Departments of Dermatology and Plastic Surgery, St. George's Hospital, London S.W.1

BARBARA LEPPARD, M.B., M.R.c.P., Senior Registrar (Present address: St. John's Hospital for Diseases of the Skin, London W.C.2) K. V. SANDERSON, M.B., F.R.C.P., Physician

F. BEHAN, F.R.A.C.S., F.R.C.s. First Assistant Plastic Unit
}

\section{Introduction}

Since Hutchinson ${ }^{2}$ first described it melanotic whitlow has remained a problem in diagnosis. He pointed out that though it looks like a chronic whitlow careful observation will show the pigmented band bordering the inflamed area. He remarked that the diagnosis is always missed in the early stage; subsequent descriptions and the following case reports show that this is still true. It is seen early by the patient but diagnosed late by the doctor: ${ }^{3}$

Case 1.-A 61-year-old housewife was first seen at another hospital in July 1969 with a painful right ingrowing toenail. The nail was apparently very deformed and necrotic and was removed under general anaesthetic. The wound did not heal and no nail regrew. Eleven months later the right great toenail bed was red and macerated and the left great toenail was "ingrowing." The nail bed of both great toes was excised but not histologically examined. Neither wound healed though the patient was in hospital for several weeks. She was referred to us in September 1971 because the wounds had still not healed, and she said that two to three weeks previously a pigmented band had developed in the red friable area on the dorsum of the right toe. 
Examination of the right great toe showed two seperate lesions (fig. 1). The larger was an irregular red friable mass 14 by 22 $\mathrm{mm}$ in diameter with a dark brown edge. A smaller brown nodule lay just proximal to the lateral margin. The left great toenail showed a 4 by $2 \mathrm{~mm}$ red nodule which had the appearance of granulation tissue. There was no pigmentation around it and no other abnormality was found either clinically or on laboratory or $x$-ray investigation. Biopsy samples from both toes showed malignant melanoma and amputation at the metatarsophalangeal joint of both great toes was carried out. The patient remains alive and well two years later.

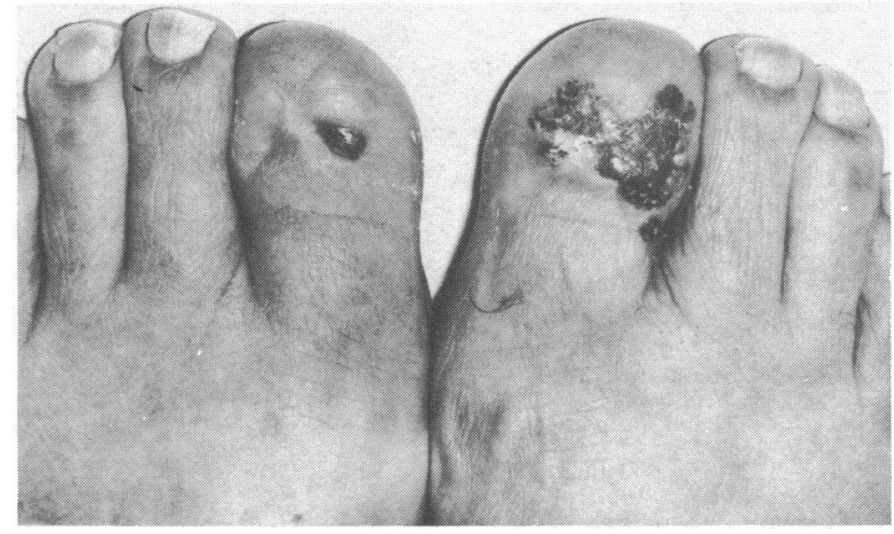

FIG. 1-Case 1. Tumour on both great toes.

Histologically the right toe showed marked junctional activity with clumps of polygonal malignant melanoma cells extending down into the subcutaneous fat. Pigment was present both intracellularly and extracellularly. The tumour was very vascular, with widely dilated blood vessels throughout (fig. 2). The lesion from the left toe showed a similar tumour which was also very vascular and contained much pigment. Junctional activity was present, suggesting that this was a second primary tumour.

During the past seven years three further patients with subungual melanomas have been seen at St. John's Hospital for Diseases of the Skin and each of these caused some difficulty in diagnosis.

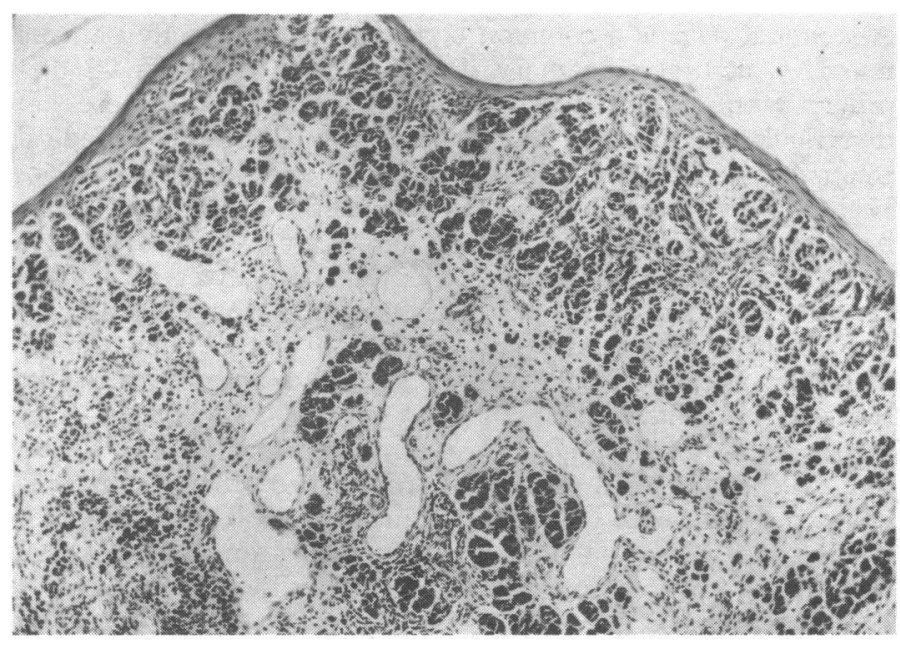

FIG. 2-Case 1. Histological specimen showing very vascular tumour with marked junctional activity. (H. and E. $\times 58$ ).

Case 2.-A 59-year-old spinster was first seen in January 1966 with a 10-month history of a split right index fingernail (fig. 3). There was no history of preceding injury and the lesion was not painful. Local treatment with corticosteroid creams and lotions for two years did not help and she was then not seen for two years. When seen again in May 1970 she had developed a white wartlike lesion at the base of the nail and the nail itself had largely disintegrated. Excision of the nail and nail bed was performed and a histological specimen showed an amelanotic malignant melanoma. The right index finger was amputated through the proximal interphalangeal joint. The patient remains alive and well three years later.

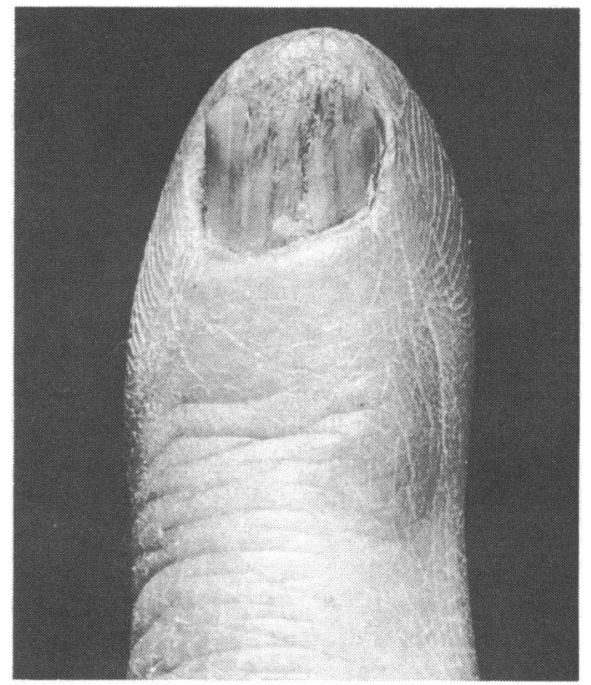

FIG. 3-Case 2. Split right index fingernail.

Case 3.-A 50-year-old housewife was first seen in December 1966. She had noticed that the lateral side of the left great toenail had become black 10 years previously and that the discoloration had gradually spread to the whole nail. There was no history of preceding trauma and the nail was not painful. On examination the nail was black and the skin of the posterior nailfold was also brownish black (fig. 4). The toe was amputated, and microscopical examination confirmed the diagnosis of malignant melanoma. Four years later a femoral gland was found to contain secondary tumour. Subsequently, a further gland appeared in the left groin but she remained well.

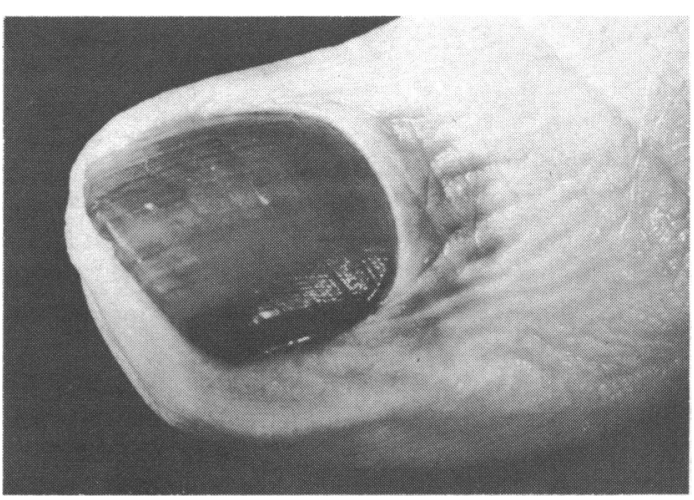

FIG. 4-Case 3. Left great toe after removal.

Case 4.-A 51-year-old housekeeper was seen in July 1967 complaining of a painful swollen left thumb. She had injured it one year previously and it had been painful ever since. It was first thought to be a chronic paronychia since it was not pigmented. The clinical appearance, however, was suspicious and the thumb was amputated. Histological examination showed a malignant melanoma. Eighteen months later she developed amelanotic 
secondary deposits in the left axilla, followed six months later by a malignant left pleural effusion. Shortly after this she left London. She was not seen again and presumably has died.

\section{Discussion}

Subungual melanoma is uncommon. It occurs in middle-aged and elderly patients and most commonly affects the thumbnail or great toenail.45 Malignant melanoma is more common in women than men, ${ }^{6}$ but subungual melanomas occur equally often in both sexes. There is a relatively high incidence in Negroes, ${ }^{6}{ }^{8}$ when one considers that malignant melanoma is rare in that race. ${ }^{\circ}$

The palms, soles, genitalia, and subungual areas have an increased incidence of malignant melanoma proportional to their surface area. This has been attributed to trauma but is more likely to be related to the fact that moles in these areas usually remain as junctional or compound naevi. ${ }^{10}$ Only relatively few moles on the rest of an adult's body show junctional activity. Many patients attribute the onset of their tumours to trauma, ${ }^{411}$ but more probably when the lesions are injured they do not heal and are therefore noticed.

Primary melanoma is diagnosed microscopically by the presence of junctional activity; secondary tumours are said to remain entirely beneath the epidermis. ${ }^{12}$ Multiple primary melanomas are said to occur in $3.6 \%$ of patients with malignant melanoma. ${ }^{10}$

Of particular interest in one of our patients (case 1) was the symmetry of the lesions. Peterson et al. ${ }^{6}$ described five patients with multiple primary malignant melanomas, of which three showed bilaterally symmetrical lesions; other workers have not noticed this. Duperrat ${ }^{7}$ described a patient (case 13) who had a painful subungual melanoma of his right index finger and who, one year later, developed a painful pigmented lesion under his left great toenail. This was thought clinically to be a second melanoma but histological examination showed it to be a glomus tumour.

The present patients were thought to be suffering from ingrowing toenails, simple split nail, junctional naevus, and chronic paronychia before the correct diagnosis was made. In three of the four patients no pigmentation was visible in the early stages, and in two the tumours were amelanotic when they were removed. Such lesions usually look inflammatory and are almost never diagnosed clinically. ${ }^{13}$ Malignant melanoma should be considered as a possible cause of any persistent abnormality of the nailbed or the nail itself, whether it is pigmented or not. ${ }^{13} 14$ Only half of the cases are diagnosed within two years of the tumour appearing and $30 \%$ of patients already have metastases in the lymph nodes when they are first seen. ${ }^{14}$ The prognosis ought to be better than for malignant melanoma elsewhere because a wide margin of excision is guaranteed if the digit is removed, ${ }^{15}$ provided the correct diagnosis is made initially.

We should like to thank Drs. Gold, Forman, Samman, and Wilson Jones for permission to report on patients under their care, and Professor J. S. Calnan and Mr. A. K. Munro for followup details of patients.

\section{References}

1 Hutchinson, J., American fournal of the Medical Sciences, 1886, 91, 470.

2 Hutchinson, J., British Medical fournal, 1886, 1, 491.

3 Pack, G. T., and Adair, F. E., Surgery, 1939, 5, 47

4 Newell, C. E., Southern Medical fournal, 1938, 31, 541

Newell, C. E., Southern Medical Fournal, $1938,31,541$. ack, G. T., and Oropeza, R., Surgery, Gynecology and Obstetrics, 1967, 24, 571.

- Petersen, N. C., Bodenham, D. C., and Lloyd, O. C., British fournal of Plastic Surgery, 1962, 15, 49.

7 Duperrat, B., Semaine des Hôpitaux de Paris, 1962, 38, 304.

Bergera, J. J., and Hirst, R. N., Plastic and Reconstructive Surgery, 1969, 44, 395.

- Sutton, L. A., and Mallia, W. M., Archives of Dermatology and Syphilology, $1923,8,325$.

${ }^{10}$ Allen, A. C., and Spitz, S., Cancer, 1953, 6, 1.

11 Rushforth, G. F., British fournal of Surgery, 1971, 58, 451

12 Greenhalgh, R. M., Talbot, I. C., and Calnan, J. S., British fournal of Plastic Surgery, 1971, 24, 301 .

13 Wortzel, M. H., fournal of the Medical Society of New fersey, 1965, 62, 435.

14 Gibson, S. H., Montgomery, H., Woolner, L. B., and Brunsting, L. A. fournal of Investigative Dermatology, 1957, 29, 119.

15 Pack, G. T., Gerber, D. M., and Scharnagel, I. M., 1953, Proceedings of Third Conference on Biology of Normal and Atypical Pigment Cell Growth, ed. M. Gordon, p. 177. New York, Academic Press, 1953.

\section{PRELIMINARY COMMUNICATIONS}

\section{Colonic Response to Pentazocine}

\section{STANCIU, JOHN R. BENNETT}

British Medical fournal, 1974, 1, 312-313

\section{Summary}

The effects of pentazocine on colonic motor activity were studied in five normal subjects, five patients with irritable bowel syndrome, and five patients with diverticular disease. The drug decreased intraluminal colonic pressures in all patients but one. Since morphine, which increases intraluminal colonic pressures, is contraindicated in patients with abdominal pain of colonic origin (diverticular disease, irritable bowel syndrome), we suggest that pentazocine may be a useful drug in such cases.

Gastrointestinal Unit, Hull Royal Infirmary, Hull HU3 2JZ

C. STANCIU, M.D., Research Fellow in Gastroenterology

JOHN R. BENNETT, M.D., M.R.C.P., Consultant Physician

\section{Introduction}

Abdominal pain is a common complaint due in many patients not to structural alimentary disease but to "functional" disordens with abnormal intestinal motility. Among these are diventicular disease and the irritable colon syndrome. Medical treatment of these conditions (Painter and Truelove, 1964; Waller, 1971) may relieve pain but sometimes the patient may need an analgesic drug. Painter and Truelove (1964) have shown that morphine and other opium derivatives may make abnormal motility wonse by increasing the power of already abnormally strong contractions of smooth muscle, and though pethidine is one alternative its addictive propenties make its repeated use undesirable.

Studies in animals (Danhof et al., 1966; Danhof and Blackmore, 1967) and man (Danhof, 1967) showed that pentazocine delayed gastric emptying and diminished small intestinal propulsive motility. The actions of the drug on the abnormal large bowel have not previously been described, and we repont its effects on colonic motor aotivity in normal subjects and in patients with abdominal pain due to the irritable bowel syndrome or diventicular disease.

\section{Subjects and Methods}

The subjects studied were five normal men aged 19 to 22 